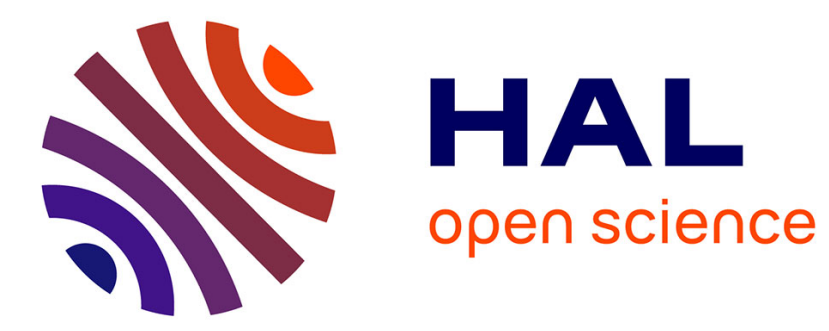

\title{
Behavior of High Strength Fiber-Reinforced Concrete beams under cyclic loading
}

Laurent Daniel, Ahmed Loukili

\section{To cite this version:}

Laurent Daniel, Ahmed Loukili. Behavior of High Strength Fiber-Reinforced Concrete beams under cyclic loading. Structural Journal, 2002, 99 (3), pp.248-256. 10.14359/11908 . hal-01005287

\section{HAL Id: hal-01005287 \\ https://hal.science/hal-01005287}

Submitted on 2 Mar 2017

HAL is a multi-disciplinary open access archive for the deposit and dissemination of scientific research documents, whether they are published or not. The documents may come from teaching and research institutions in France or abroad, or from public or private research centers.
L'archive ouverte pluridisciplinaire HAL, est destinée au dépôt et à la diffusion de documents scientifiques de niveau recherche, publiés ou non, émanant des établissements d'enseignement et de recherche français ou étrangers, des laboratoires publics ou privés. 


\section{Behavior of High-Strength Flber-Reinforced Concrete Beams under Cyclic Loading}

by Laurent Daniel and Ahmed Loukill

This study investigated both the influence of longitudinal steel ratio and steel fiber length on high-strength concrete (HSC) beams' behavior under altermate cyclic bending. The evolution in both structural properties and cracking patterns was compared
with results from the monotonic bending sest. To observe the influence of fibers on deterioration of mechanical properties due to loading cycles, high-strength fiber-reinforced concrete (HSFRC) beams were rested using two fiber lengths: 30 and $60 \mathrm{~mm}$. This analysis highlighted the positive effect of fibers on bothe esecan structura stifness and the cracling pattems diring the prepeak stage. For the postpeak stage, the ductility measurement easurement of cyclic dissipated energy is an important parameter in evaluating structural behavior. Within this framework, the positive effect of fibers on energy dissipation as well as on the cumulative damage capacio has been underscored.

Keywords: crack; fiber-reinforced concrete; high-strength concrete.

\section{INTRODUCTION}

It is well-known that high-strength concrete (HSC) is a material featuring many favorable aspects, not only by virtue of its high compressive strength, but also through its durability improvements. The mechanical have revealed the britleness of Hse and reaced the use C USC in earthquake zones as a result of recommendation (t) importance of obtaining a ductile material. It is important, however, to mention that, in the case of a high-strength reinforced concrete beam, the structura ductility ${ }^{4}$ of HSC can be similar to or better than that of ordinary reinforced concrete beams if the failure mode occurs by steel failure. During an earthquake, however, structures are subjected to reverse loads, which induce both severe tensile damage of concrete and bond deterioration. Hence, the postpeak behavior is particularly influenced by the tensile and bond strength of the concrete.

Previous investigations have shown the effectiveness of fibers on the cracking propagation. ${ }^{6}, 7$ The greatest improvement involved the increase of dissipated energy, characterized by the uniaxial compressive or tensile behavior of a softened postpeak slope. ${ }^{8}$ This focus has served to guide certain studies on structural applications and has pointed out the effective ness of fibers on cracking control and on shear and bending capacities. 'The intuence of thers on the structural failure mode, however, depends on al results such as those retype, and concrete. Experime bspion, Devillers, and Halleux ${ }^{10}$ indicated the inefficiency of fibers in ductility increase, and can be opposed to the results given by Chunxiang and Patnaikuni ${ }^{11}$ that reto the results given by Chunxiang and Pataility. These controversial results pointed out the qualified use of fibers under
Table 1-Concrete mlxture proportions

\begin{tabular}{c|c|c}
\hline Components, $\mathrm{kg} / \mathrm{m}^{3}$ & $\begin{array}{c}\text { High-strength } \\
\text { concrete }\end{array}$ & $\begin{array}{c}\text { High-strength fiber- } \\
\text { reinforced concrete }\end{array}$ \\
\hline Cement & 400 & 400 \\
\hline Silica fume & 40 & 40 \\
\hline Filler & 72.2 & 69 \\
\hline Sand, 0 to $5 \mathrm{~mm}$ & 722 & 690 \\
\hline Gravels, 6 to $10 \mathrm{~mm}$ & 1010 & 966 \\
\hline Hight-range water-reducing admixture & 6 & 10 \\
\hline Water & 140 & 134 \\
\hline Fibers & 0 & 79 \\
\hline
\end{tabular}

monotonic load, but few papers deal with the influence of fibers on structural behavior under cyclic load.

The purpose of this paper is to examine the influence of fibers on cyclic beam-bending behavior (cyclic test). Two lengths of fibers are used: 30 and $60 \mathrm{~mm}$. As a tradeoff between loss of workability and increase in structural strength, a reasonable level of steel fibers was chosen: $1 \%$ (by volume). To remain close to the structural dimensions used in civil engipeering practice, a beam length of $2.75 \mathrm{~m}(0.11 \mathrm{ft}$ ) and a cross section of $150 \times 300 \mathrm{~mm}(6 \times 12 \mathrm{in}$.) are used. The influence of tensile reinforcement is studied by including

\section{RESEARCH SIGNIFICANCE}

This study reports useful data on the application of highstrength fiber-reinforced concrete (HSFRC) in a seismically active zone. It has been shown that reverse loads involve severe bond deterioration. The control of macrocracks by fibers enhances not only the mechanical properties of highstrength concrete in tension and compression, but also the structural behavior. According to Lemaitre and Chaboche, mechanical properties of HSFRC, such as strengh and duetly, this work brings some information about structural behavio enhancement by fibers with respect to both the length of fiber and to the longitudinal reinforcement ratio used. These result broaden the application of fibers to reinforced concrete structures in seismically active zones.

\section{MATERIAL PROPERTIES}

Three types of concrete were used for the purposes of thi (HSFRC 30 ), and HSFRC with a fiber length of $60 \mathrm{~mm}$

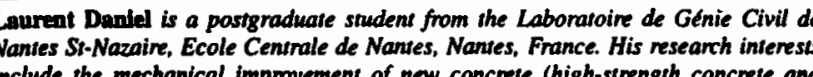

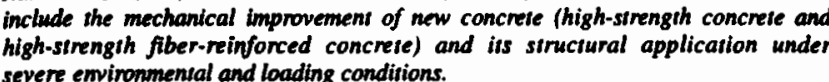
ACl member Anmed Louldill is an assistant professor in the Laboratoire de Gente

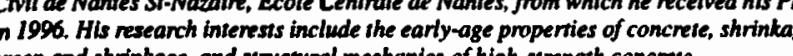

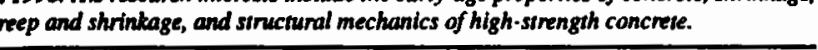
(HSFRC ${ }_{60}$ ). The mixture components for these concretes are given in Table 1.

A portland cement with low $\mathrm{C}_{3} \mathrm{~A}$ content was used. Undensified silica fume was added at a proportion of $10 \%$ of cemen mass. The water-binder ratio was 0.32 . To avoid a loss of horkabilly dae to the inclusion of fibers, the quantity of 0.54 10 $1 \%$ dy extact of centre 0 the factor, ${ }^{4}$ and the optimum value used in the fibers' reinforced concrete production is $l / d_{f}=80$. This ratio has therefore been chosen for the two types of fibers. The fiber volume we constant at $1 \%$. Fiber characteristics are displayed in Table 2 . Compressive tests were carried out on $110 \times 220 \mathrm{~mm}$ (4.3 $8.6 \mathrm{in}$.) cylindrical specimens after 28 days using a testing machine under load control at a loading rate of $0.5 \mathrm{MP} / \mathrm{s}$. The concrete specimens were kept at $20^{\circ} \mathrm{C}$ and $95 \%$ relative humidity during the setting process, and then demolded 24 b casting. Compressive tests were performed on three specimens for each type of concrete, and results are presented maty $95 \mathrm{MPa}(13.8 \mathrm{ksi})$, with a strain at peak of $2.4 \%$. The mately $95 \mathrm{MPa}(13.8 \mathrm{ks})$, with a strain at peak of $2.4 \%$. The with an average value of $112 \mathrm{MPa}(16.2 \mathrm{ksi})$ for $\mathrm{HSFRC}_{30}$ and $118 \mathrm{MPa}(17.1 \mathrm{ks}$ ) for $\mathrm{HSFRC} 60$. The strain at peak was for HSFRC $_{60}$, and highlighted the ability of HSFRC to store a higher quantity of energy in the prepeak domain than HSC.

\section{EXPERIMENTAL PROGRAM}

The general test setup and beam cross section are described in Fig. 1(a). A dynamic actuator was used to apply reverse loads on beams $2.75 \mathrm{~m}$ in length and $150 \times 300 \mathrm{~mm}$ in cross section. A positive and negative loading direction was introduced by means of a threaded rod system linked to the beam. The span-depth ratio a/d was chosen to obtain bending failure. To generate failure between the loading points, stimups diameter of $8 \mathrm{~mm}$, spacing of $20 \mathrm{~cm}$ ) were arranged outside the pure bending zone. The influence of the reinforcement on beam behavior was analyzed by testing three different values for the tensile reinforcement ratio $(0.55,0.97$ and $1.52 \%)$ using longitudinal bars 12,16 , and 20 The steel was Type FeE500 (tensile yield strength: $500 \mathrm{MPa}$ ). Each support was fitted with a swiveling frame that prevented vertical displacement but allowed rotation about the $z$-axis (Fig. 1(b)). The horizontal displacement was introduced by ollers arranged on one of the supports.

The cyclic tests were displacement controlled. A $0.5 \mathrm{~Hz}$ loading frequency was selected to reach the ultimate state of the beams. To measure strength deterioration at a given amplitude deflection, the loading sequence (Fig. 2) was adjusted to Tab Table 3.

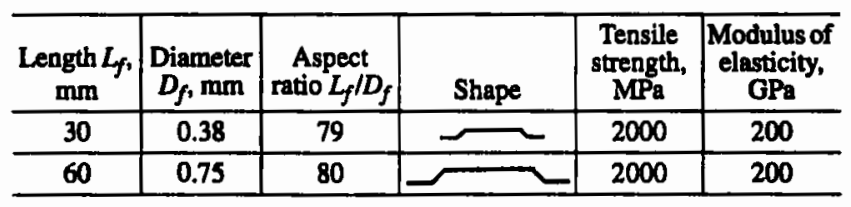

\section{Table 3-Details of beam serles}

\begin{tabular}{c|c|c|c|c}
\hline Beam type & Steel ratio $\rho, \phi \mathrm{mm}$ & Loading & Concrete & $f_{c} \mathrm{MPa}$ \\
\hline
\end{tabular}

\begin{tabular}{|c|c|c|c|c|}
\hline & . & & & \\
\hline L-ref & \multirow{3}{*}{$0.55 \%(12 \mathrm{~mm})$} & \multirow{3}{*}{ Cyclic } & $\mathrm{HSC}$ & 97 \\
\hline L-30 & & & $\mathrm{HSFRC}_{30}$ & 110 \\
\hline$L-60$ & & & $\mathrm{HSFRC}_{60}$ & 116 \\
\hline M-ref & \multirow{4}{*}{$0.97 \%(16 \mathrm{~mm})$} & Static & HSC & 91 \\
\hline & & \multirow{3}{*}{ Cyclic } & HSC & 95 \\
\hline M-30 & & & $\mathrm{HSFRC}_{30}$ & 112 \\
\hline M-60 & & & HSFRC $_{60}$ & 117 \\
\hline & \multirow{4}{*}{$1.52 \%(20 \mathrm{~mm})$} & Monotonic & HSC & 97 \\
\hline $\mathrm{n}-\mathrm{rt} \mathbf{1}$ & & \multirow{3}{*}{ Cyclic } & HSC & 94 \\
\hline $\mathrm{H}-30$ & & & $\mathrm{HSFRC}_{30}$ & 114 \\
\hline $\mathrm{H}-60$ & & & HSFRC $_{60}$ & 117 \\
\hline
\end{tabular}
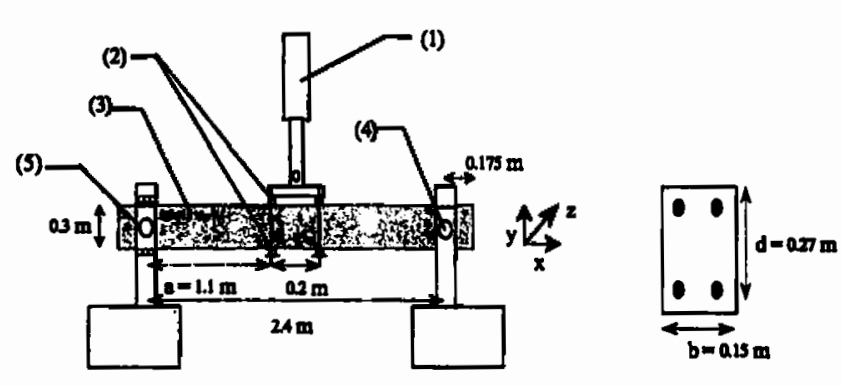

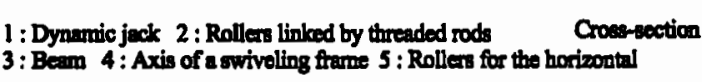

(a)

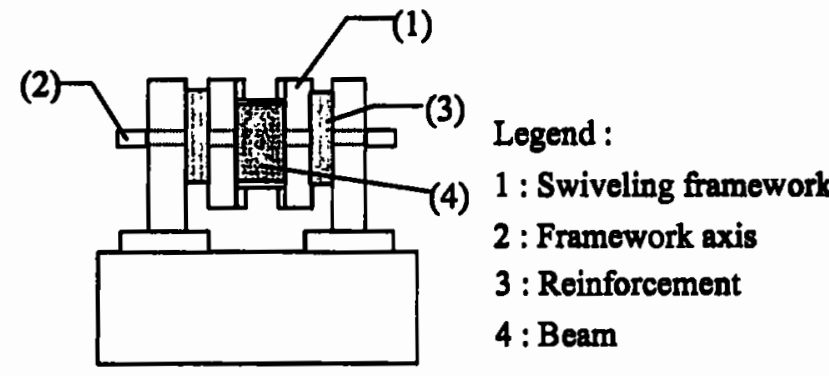

(b)

Fig. 1-(a) Testing setup and beam cross section; and $(b)$ alternate bending supports.

BOND DETERIORATION UNDER REVERSE LOADS A cyclic loading is the worst case of loading, as each concrete layer is alternately submitted to tension and compression stresses. Concrete and steel-concrete bonds are severely damaged. The bond deterioration mechanism observed by Popor is described in Fig. 3(a) to (d) and relates to the typical cyclic load deflection curve presented in Fig. 4 ,

Before the peak load: During the positive loading (Fig. 3(a)), the difference between the steel and concrete Toung meduli generates bond stesses. Once the limit 


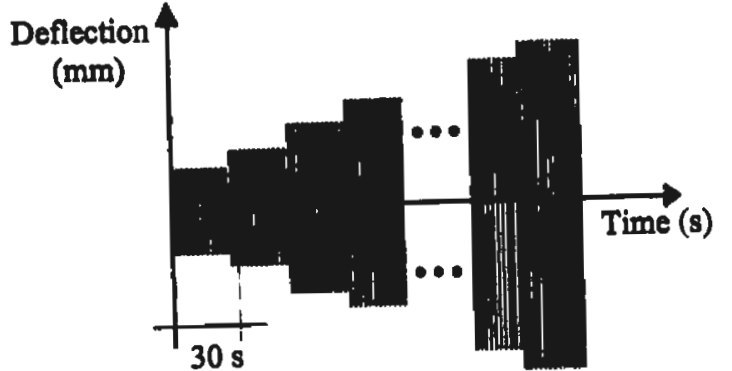

Fig. 2-Loading sequence.

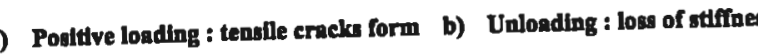
ensile cracks
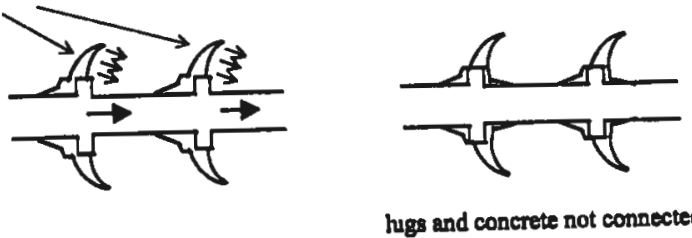

c) Negative loadlog: aln of ottingens Anter the Umit band strength

New crack form

After the peak load: Bond deterioration is severe - (Fig. 3(d)), and the residual steel strain is very high. Consequently, during a reverse load, the tensile stee Consequently, during a reves the closure of previous strain remains and prant stiffness cannot be increased and the pinching disappears (Fig. 4).

tensile cracks closed

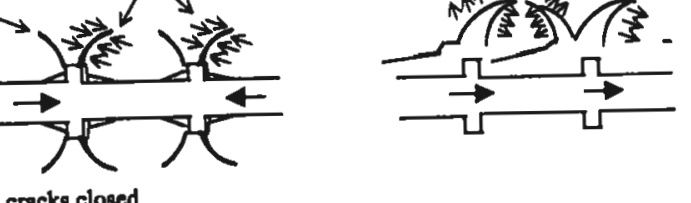

Fig. 3-Bond deterioration mechanism.

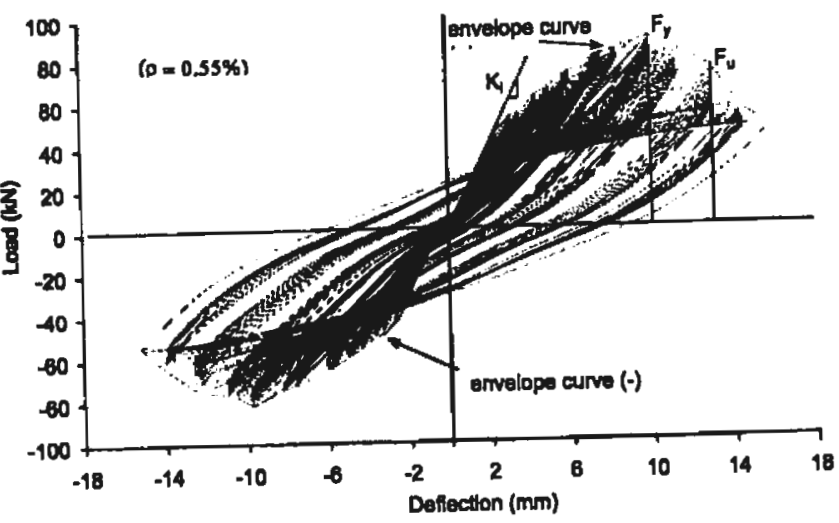

4 Typical cyclic curve and envelope curve (HSFRC 30 beam)

occur and low anelastic strain remains (Fig. 3(a)). During unloading, the secant structural stiffness $K$ on the load-deflection curve is regulated both by the strai of tensile bars and by the strain of the compressive zone. Once the load is close to zero, lugs and concrete are no longer connected, and compressive forces are used to close the tensile cracks (Fig. 3(b)). This mechanism involves a decrease in secant structural stifness up until the closure of the tensile cracks and the connection between lugs and concrete (Fig. 3(c)). The secant stiffness can then be increased and new generated due to compressive strsses of the durs, the loading phases; and $0.97 \%$ st $p=152 \%$, respectively. The analysis focused both the cracking pattern and the load-deflection curves. Fig. 5(a) and (b). The reverse loads prevent the concret from crushing but the cracks propagate throughout the deph inducing horizontal cracking.
Table 4-Effect of loading type on mechanical propertles

\begin{tabular}{|c|c|c|c|c|c|c|c|c|c|c|}
\hline \multirow{3}{*}{$\underline{p, \%}$} & & & \multicolumn{4}{|c|}{ Monotonic loading } & \multicolumn{4}{|c|}{ Cyclic loading } \\
\hline & \multicolumn{2}{|c|}{ Load level } & Lood, $\mathrm{kN}$ & Deflection, $\mathrm{mm}$ & $K, \mathrm{kN} / \mathrm{mm}$ & $\mu_{\delta}$ & Load, $\mathrm{kN}$ & Deflection, $\mathrm{mm}$ & $K, \mathrm{kN} / \mathrm{mm}$ & $\mu_{8}$ \\
\hline & A & - & \begin{tabular}{|l|}
27.9 \\
\end{tabular} & $\begin{array}{l}1.3 \\
\end{array}$ & \begin{tabular}{|l|}
21.1 \\
\end{tabular} & - & 32.0 & \begin{tabular}{|l|}
1.4 \\
\end{tabular} & 22.9 & - \\
\hline \multirow{2}{*}{0.97} & B & $F_{\text {max }}$ & 102.0 & 18.0 & 5.7 & - & 91.6 & 10.3 & 8.9 & $=$ \\
\hline & c & $-15 \%$ & 86.5 & 43.0 & 2.0 & 2.38 & 76.6 & 15.6 & 4.9 & 1.52 \\
\hline \multirow{3}{*}{1.52} & A & - & 29.2 & 1.9 & 15.6 & - & 30.9 & 2.0 & 15.1 & - \\
\hline & B & $F_{\max }$ & 166.8 & 17.6 & 9.5 & - & 152.9 & 15.1 & 10.1 & $=$ \\
\hline & c & $-15 \%$ & - & - & - & - & 130,0 & 18.3 & 7.1 & 1.22 \\
\hline
\end{tabular}

cases. One example of such an envelope curve is drawn in Fig. 4. A comparison of different curves is provided in Fig. 6 , and some mechanical properties are given in Table 4.

Before the peak load, it has been noted that alternate loading does not change the secant stiffness of the HSC by approximately $10 \%$.

Beyond the peak load, the slope of the cyclic curve drops Beyond the peak load, the slope of tin syctic crue drops This ductility is defined as the ratio of ultimate deflection to the deflection at the peak load $\delta_{\mu} / \delta_{F \max }$. A study of this structural ductility was the topic of another paper. ${ }^{15}$ The ultimate deflection corresponds to the deflection measured at $85 \%$ of the peak load. For $\rho=0.97 \%$, the cyclic loadin decreases the ductility by $36 \%$. For $\rho=1.52 \%$, data acquisition was not performed beyond the postpeak, but it was thought that the loss in ductility would not be so high as a result of the greater brittleness of beams exhibited by the increase of tensile reinforcement under monotonic loading. Cracking degrades the steel-concrete bond. As long as the anchrage of bars and the force redistibution in the comsimilar. Under alternate stresses, both the cyclic softening of materials 12 and the time lag of the force redistribution in of materials and the time lag of the force redistribution in postpeak branch.

The cracking zone can be observed in over a wider zone. Moreover, a greater number of horizontal cracks are located at the level of the steel bars, thereby demonstrating the severity of steel-concrete bond deterioration. The minimal and maximal spacings measured in static tests are close to those obtained by Maurel ${ }^{14}$ on beams with a similar cross section and a shear span of $0.8 \mathrm{~m}$ (minimal spacing of $5 \mathrm{~cm}$ and maximal spacing of $12.5 \mathrm{~cm})$. The longitudinal steel ratio seems to have lite inher on the spacing of cracks. The cyclic tests, however, show an incres an in the spacing of cracks within the shear, zone, and thus, an increase in maximal spacing. This finking can be explained by the different stages of the cracking process. Al and bending cracks occur similar cracks alternate loads, steel-concrete debondin reduces the rate of occurrence of transverse cracks whilo

Load-deflection curves
As a means of comparing tests under monotonic and cyclic loads, average envelope curves have been used in the cyclic
The influence of fibers on the apparent cracks can be visualized in Fig. 7(a) to (c), which have been extracted

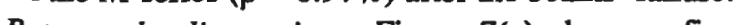
straight loading points-Figure 7 (a) shows a fine and

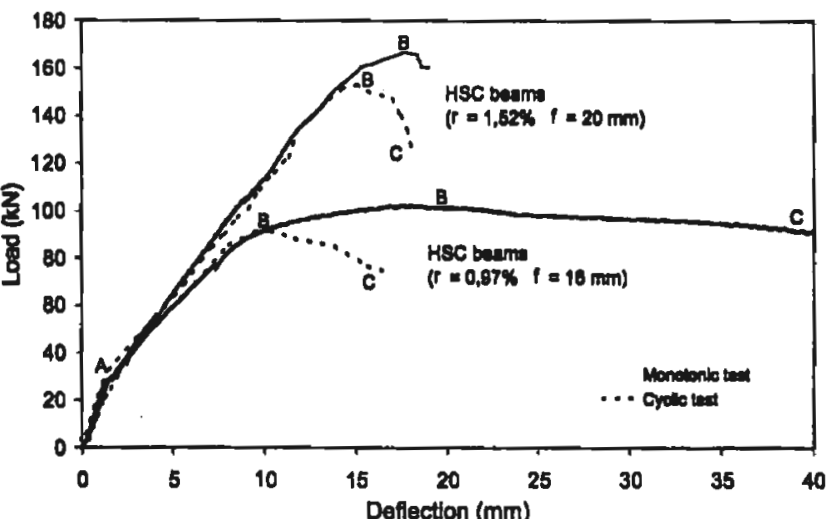

Fig. 6-Static and cyclic tests on HSC beams.

more sinuous when fibers are added (Fig. 7(b) and (c)). It is mportant to note that this observation is made at the end of test. Indeed, if fibers are often used to reduce the crack width during service loads, their bridge effect allows a increase of the main crack width during the failure stage. The measure of the crack width, however, was not recorded due to the difficulties induced by both alternated loads and

For the M-30 test, fibers induce a multicracking on the upper part of the beam. At the loading points, bending cracks propagate throughout the beam height for both the $\mathrm{L}$-ref and M-ref series; with the long fibers, however, some b

Outside loading points-The HSC beams display some Oulside lod bus did the deterioration of the steel-concrete bond (Fig . 7(a)). With the addition of fibers, both the number and length of crack are reduced (Fig. 7(b) and (c)). The shear cracks seem to be effectively bridged by the fibers. Moreover, the horizontal cracks are not located on the HSFRC beams and reflect the action of fibers on cracking induced by steel-concrete debonding. Some isolated cracks can be noted, however, which suggests the random bridging effect of fibers inside the cross sections.

Influence on load-deflection envelope curves Figure 8 presents cyclic envelope curves that resulted by taking an average of positive and negative envelope curves. The deflection gain at the peak load is insignificant; the curves were thus drawn with respect to a normalized deflection relative to the peak deflection, and correspond to the definition first is a structural bevior without any damage, as chat 
Table 5-Results of tested beams
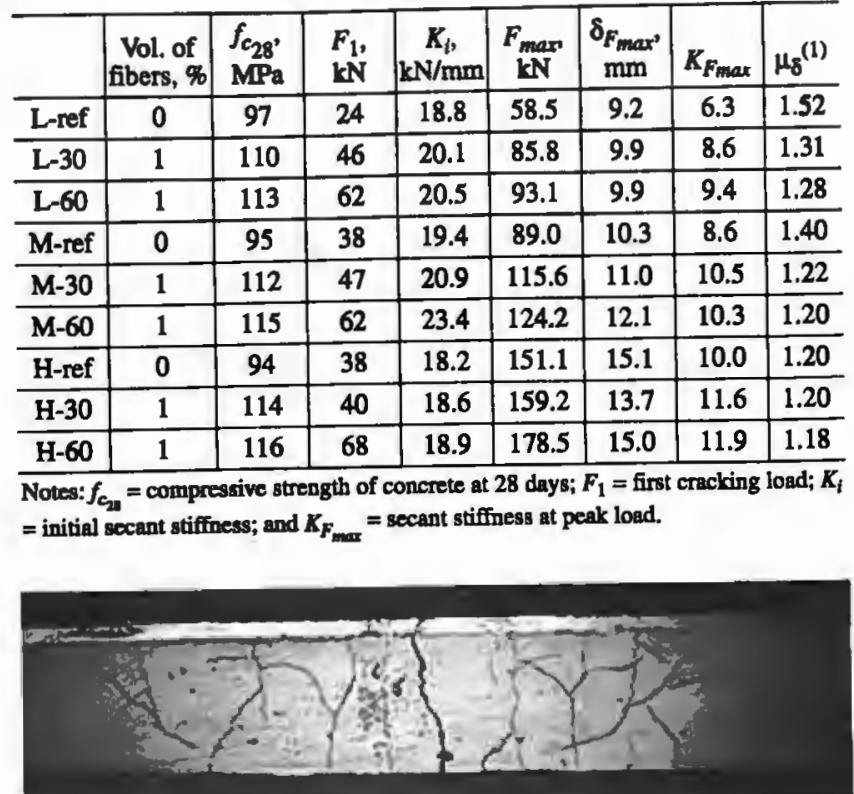

a) M-ref

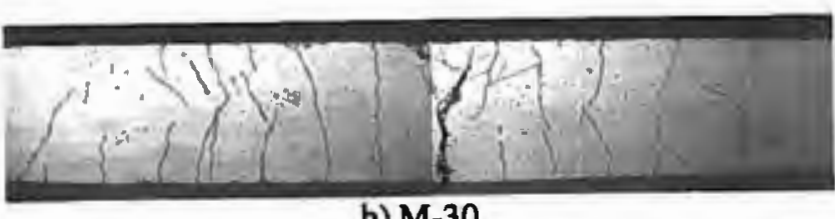

b) $\mathbf{M}-30$

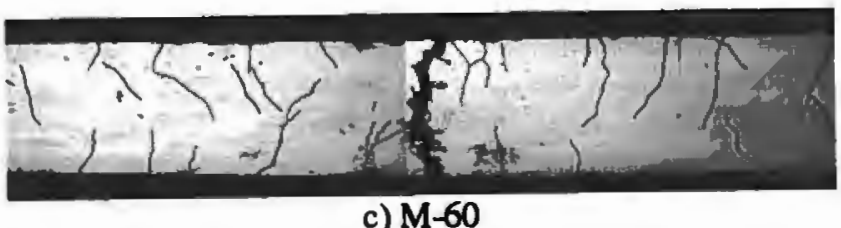

c) $\mathbf{M}-60$

Fig. 7-Bending and shear cracks on $M$-series.

acterized by the secant initial stiffness $K_{i}$ and the first cracking oad $F_{1}$; the second stage is the damaged behavior up un the maximal load applied with a decreasing secant stiffness and the last stage is the postpeak behavior that induces structural collapse. The specif
curves are listed in Table 5 .

Undamaged behavior (prepeak)-The initial secan stiffness, as shown in Table 5, is hardly increased by the presence of fibers; no real difference between $\mathrm{HSFRC}_{30}$ and HSFRC $_{60}$ can be observed. The beam's behavior is still elastic, it seems that only microcracking occurs inside the matrix. To enhance this initial stiffness, fibers would have to bridge these microcracks; consequently, the length of fibers needs to be shorter ${ }^{7}$ (maximal length: $13 \mathrm{~mm}$ ). With the length of fibers used in this work (that is, 30 and $60 \mathrm{~mm}$ ), only macrocracks are bridged as the result of the improvements brought during

When either the upper or lower concrete layer of the beam this crack not be bridged by the fibers, the tensile stress would suddenly be distributed in the tensile steel bars, and the secant structural stiffness of the beam would decrease. With HSFRC, as fiber length increases, the value of $F_{1}$ also increases. This improvement is particularly distinct at the
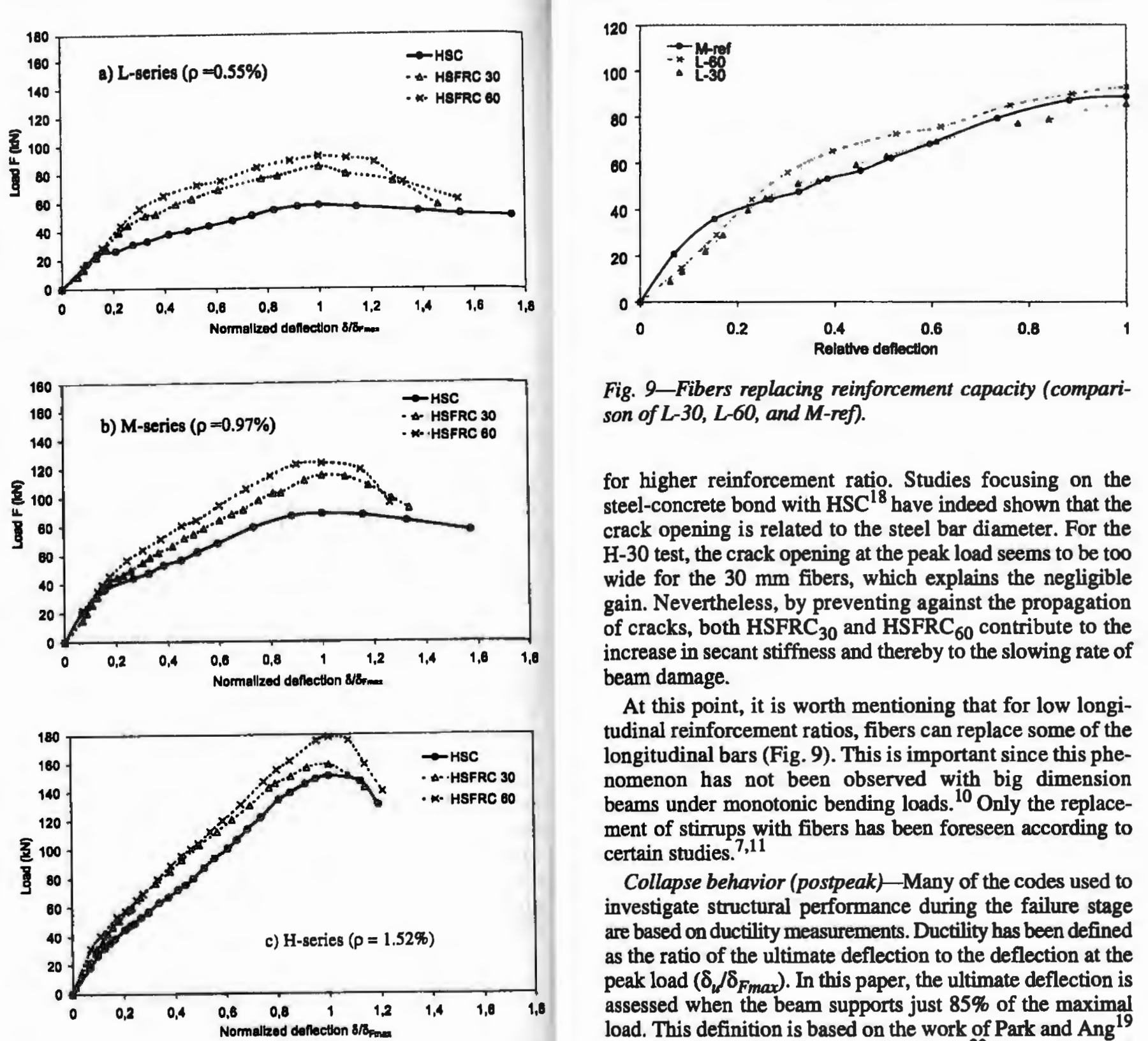

Fig. 8-Load-deflection envelope curves on $L$-, $M$-, and H-series.

low reinforcement ratio $(\rho=0.55 \%)$ since $F_{1}$ increases by $77 \%$ with $\mathrm{HSFRC}_{30}$ and by $170 \%$ with $\mathrm{HSFRC}_{60}$. This finding highlights the efficiency of fibers to delay the macrocracks propagation. Due to the secant stifness being controlled by the tensile bars, however, the value of $F_{1}$

Dame thed behior (prepeak) - In this stage, bending and Damaged behavior (prepeakat but also bond cracks, as detailed previously. The bridging of cracks by fibers induces detailed previously. The bridging of cracks by fibers induces an incers This improvementis effective throughout the loadin stage up to the peak load. The yielding of reinforcemen stage up of the peak, but no significant change of stiffnes is observed. Table 5 displays an increase in the peak load of HSFRC compared with that of HSC by 47,30 , and $5 \%$ for the L-30, M-30, and H-30 tests, respectively, and an increas of 59,40 , and $18 \%$ for the L- $60, M-60$, and H-60 tests. It caa be noted that the increase in the tensile bar ratio reduces the gain contributed by the fibers, due to a wider crack openin
Fig. 9-Fibers replacing reinforcement capacity (comparison of $L-30, L-60$, and $M-r e f$.

for higher reinforcement ratio. Studies focusing on the steel-concrete bond with $\mathrm{HSC}^{18}$ have indeed shown that the crack opening is related to the steel bar diameter. For the wide for the $30 \mathrm{~mm}$ fibers, which explains the negligible gain. Nevertheless, by preventing against the propagatio of cracks, both $\mathrm{HSFRC}_{30}$ and $\mathrm{HSFRC}_{60}$ contribute to the increase in secant stiffness and thereby to the slowing rate of beam damage.

At this point, it is worth mentioning that for low longiudinal reinforcement ratios, fibers can replace some of the longitudinal bars (Fig. 9). This is important since this phenomenon has not been observed with big dimensio beams under monotonic bending loads. Only the replacement of stimups with fibers has been foreseen according to

Collapse behavior (postpeak)-Many of the codes used to investigate structural performance during the failure stage are based on ductility measurements. Ductility has been defined peak load $\left(\delta_{h} / \delta_{\text {Fmax }}\right.$. In this paper, the ullimate deflection is pad. This defition is that was then modified by Srinivas et al 20 who considered heavily damaged beyond this level of loading capacity. of the fibers. For each series, the concrete is severely degraded by tensile stresses at peak, and the maximal load gain obtained Considering a support capacity of $95 \%$ of $F_{\max }$ the analysis conducted by Daniel and Loukili ${ }^{21}$ indicates a similar ductility obtained with $\mathrm{HSFRC}_{60}$ relative to $\mathrm{HSC}$ for the L-series and relative to $\mathrm{HSFRC}_{30}$ for the M-series. This finding underscores the influence of long fibers with a low reinforcement ratio; however, the improvement is not substantial enough, and the small sample size only indicates some trends. More exploration should be reallizd to recommend the use of fibers

\section{Influence on cumulative dissipated energy}

Measuring ductility is not the only motivation for investigating behavior during the postpeak phase. When earthquake as the ratio of the ultimate deflection to the deflection at the that under cyclic and alternate loading structures were to Table 5, the ductility measurement indicates the inefficiency bond deterioration between reinforcement bars and concrete. be dissipated for safety reasons. According to this setup, the behavior of fibers inside the matrix acts as a dissipative thus becon the measurement of dissipated energy could

During cyclic tests on structures, dissipative mechanisms

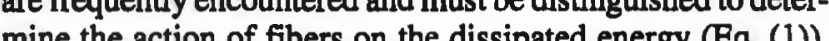
In fact, a principal energy $E_{T}$ is injected into the structure, composed of a beam or column and supports. of this energy is redistributed into the soil $E_{s}$, while the other is used by the structure over the elastic $E_{\text {s }}$ and inelastic $E_{a}$ domains. The first component $E_{e}$ represents the energy necessary both for beam displacement (kinematics energy $E_{c}$ ) and for elastic strain $E_{e s}$. The latter component $E_{a}$ includes damping energy and hysteretic energy

elastic domain inelastic domain

$$
E_{T}-E_{s}=\underbrace{E_{c}}_{E_{c}+E_{e s}}+\underbrace{E_{a}}_{E_{d}+E_{h}}
$$

Structural collapse corresponds herein to the case observed when the structure is no longer able to dissipate the accumulated energy. It is therefore important to increase the energy storage capability in the elastic domain and the energy dissipation in the inelastic domain. For the first aforementioned point, the use of of the steel-concrete bond. The low tensile strength and brittle nature of concrete, however prevent the possibility of increasing energy in the inelastic domain. Adding fibers inside the high-strength matrix limits concrete damage in the elastic domain, and results in energy dissipation in the inelastic domain due to the strain and fiber slip inside the matrix

The dissipated energy during a loading cycle was determined by computing the hysteretic area of the loop. The increase of dissipated energy during cycles at similar displacement amplitudes is low. It was thereby assumed that the contribution of fibers is concentrated during the first cycle of each displacement amplitude. The computation of primary dissipated energy was carried out up until total collapse (Fig. 10). For L-series-Fibers increase the dissipation of energy up until collapse. The gain provided by the longest fibers, compared with the shorter ones, is observed at the end of the test fim a $\left(1490 \mathrm{kNmm}\right.$ ) with respect to $\mathrm{HSC}$, while for $\mathrm{HSFRC}_{30}$ it increases by only $13 \%$.

For M-series-Only the $\mathrm{HSFRC}_{60}$ increases the dissipation of energy up until collapse, with an increase in ultimate dissipation $(2240 \mathrm{kNmm}$ ) of $41 \%$ with respect to HSC. The behavior of $\mathrm{HSFRC}_{30}$ is similar to that of HSC, with a low increase in dissipated energy over the postpeak zone. Furthermore, the maximal value is $26 \%$ less than HSC, which the low effectiveness of shorter fibers.

For $\mathrm{H}$-series-A reduction in the improvement of long fbers is noted since the maximal energy with respect to HSC increases by $28 \%$. HSFRC 30 does not show good behavior USC be las dissipation remains less than that of the HSC beam during the entire postpeak stage.

There were not enough repetidve tests to draw firm con- 

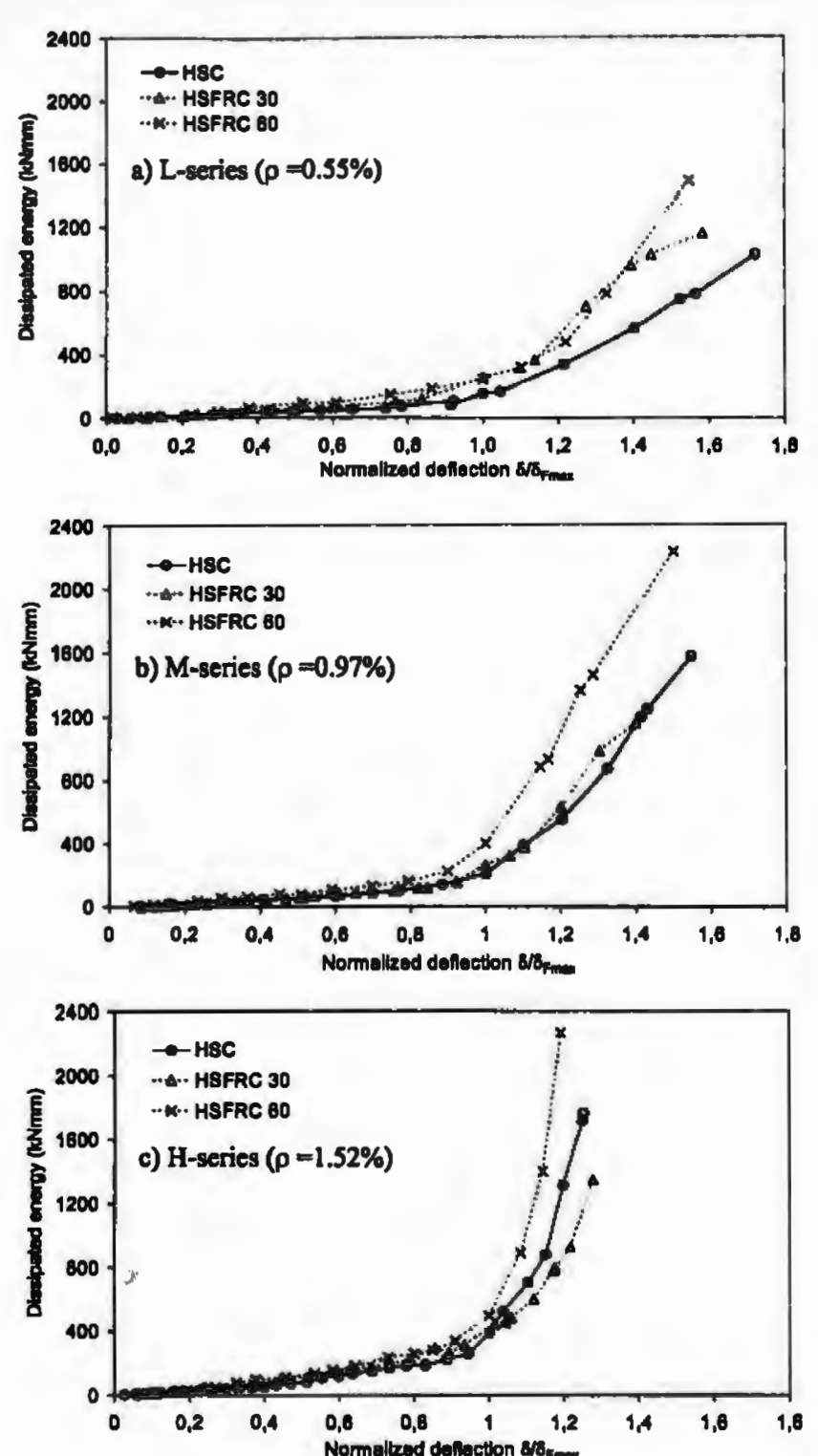

Fig. 10-Dissipated energy versus normalized deflection.

the inclusion of fibers leads to an improvement in energy dissipation, which is particularly efficient at low longitudinal steel reinforcement ratios. As the tensile bar ratio increases, the maximal dissipation rate drops. The postpeak behavior of the $\mathrm{HSFRC}_{60}$ beam can be considered as good for all series. Only the L-series, how
of the HSFRC 30 beam.

\section{STRUCTURAL DAMAGE INDEXES}

Many authors have established a set of damage indexes to ascertain the residual capacity of structures. A wide array of parameters may be used, such as number of cycles, stiffness, and ductility. When reverse loads are applied (refer to the previous section), however, the importance of energy dissipation is readily apparent. The energy indicator proposed by Darwin and Nmai provides an assessment of the dissipative capacity compared with the elastic energy injected at peak load. This measurement has been related to the hysteretic area of cycle $i, E_{i}$ normalized to the elastic energy $F_{\text {max }} \delta_{F_{\text {max }}}$. The iteration on all cycles yields the total normalized cyclic

$$
E_{n}=\frac{1}{F_{\max } \delta_{F_{\max }}} \sum_{i=1}^{n} E_{l}
$$

This indicator has been modified by Ehsani and Wright ${ }^{23}$ frness degradation and the deformation capacity (Eq. (3))

$$
D_{i}=\frac{1}{F_{\max } \delta_{F_{\max }}} \sum^{n} E_{i}\left(\frac{K_{i}}{K_{y}}\right)\left(\frac{\delta_{i}}{\delta_{y}}\right)^{2}
$$

where

$\boldsymbol{F}_{\max }$ and $\delta_{i}=$ peak load;

a dection at he peak and maximal deflec-

$E_{i} \quad=\begin{aligned} & \text { dissipated energy calculated from the are } \\ & \text { tion }\end{aligned}$ of cycle $i$; and

$K_{F_{m a x}}$ and $K_{i}=$ secant stiffness at the peak load and in cyThese last two cyclic energy in.

These last two cyclic energy indexes express numerical indexes the therefore been devised to compare the. Other dissipated under cyclic conditions with that dissipated under monotonic conditions, with numerical values ranging from 0 to $100 \%$ (100\% denotes structural failure). Meyer ${ }^{24}$ defined an indicator $D_{Q}$ based on the energy ratios in Eq. (4) and (5)

$$
D_{Q}=D_{Q}^{+}+D_{Q}^{-}-D_{Q}^{+} D_{Q}^{-}
$$

with

$$
D_{Q}^{ \pm}=\frac{\Sigma E_{p i}^{ \pm}+\Sigma E_{s i}^{ \pm}}{E_{u}^{ \pm}+\Sigma E_{i}^{ \pm}}
$$

where

$E_{p i}=$ energy dissipated during the first half-cycle;

$E_{s i}=$ energy dissipated during the second half-cycle;

$E_{\boldsymbol{u}}=$ maximum energy dissipated under monotonic load; and

$=$ positive or negative deformation

Sadeghi ${ }^{25}$ introduced a fatigue factor (Eq. (6)) to decrease the damage caused by cycles of similar amplitude displacenegative phase of displacement is given as follows (Eq. (7))

$$
D_{Q}^{ \pm}=\frac{\Sigma E_{p i}^{ \pm}+\lambda_{i}^{ \pm} \Sigma E_{s i}^{ \pm}}{E_{u}^{ \pm}}
$$

where

$$
\lambda_{i}^{ \pm}=\frac{E_{u}^{ \pm}-\Sigma E_{s i}^{ \pm}}{E_{u}^{ \pm}}
$$

The use of this index is not straightforward for structures subjected to many cycles during the postpeak phase. Moreover, loading, which would increase the number of tests required (Eq. (8)), based on the expression of Sadeghi's index (Eq. (6))

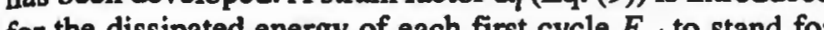
the the secant stiffness deterioration with respect to the peak doad. The damage induced by saccessive cycles of simila (Eq. (10)) related to the strength deterioration with respect to the first cycle. The energy summation is normalized by the total amount of energy dissipated by each first cycle $\Sigma F$ The tensile reinforcement ratio $\rho$ is introduced to take into account the difference in energy behavior with increasing tensile reinforcement. The power number is computed to yield an index value close to that for the HSC beams

$$
\begin{gathered}
D_{i}=\rho^{0.4} \frac{\alpha_{I}^{0.9} \sum E_{p i}+\lambda_{i}^{0.9} \sum E_{s i}}{\sum E_{p i}} \\
\alpha_{i}=\frac{K_{F_{\text {max }}-K_{p l}}}{K_{F_{\max }}} \\
\lambda_{i}=\frac{F_{p i}-F_{s i}}{F_{p i}}
\end{gathered}
$$

where

$K_{F_{\max }}=$ secant stiffness at peak load;

$\begin{aligned} K_{p i} & =\text { secant stiffness of primary cycles; } \\ F_{p i} & =\text { maximal load of primary cycles; }\end{aligned}$

$\begin{aligned} p i & =\text { maximal load of primary cycles; and } \\ F_{s i} & =\text { maximal load of successive cycles. }\end{aligned}$

The cumulative damage capacity of the beams is computed using the index in Eq. (8); results are shown in Fig. 11(a) to (c). is reduced during the first successive cycles in of damage with the HSC beam, with this distinction being particularly strong for the lower tensile reinforcement; and 2) damage related to the loss of ductility in the beams speeds up. Fo $\rho=0.55 \%$, however, both HSFRC 30 and $\mathrm{HSFRC}_{60}$ successfully increase the cumulative damage capacity with values of greater than one, yet $60 \mathrm{~mm}$ fibers appear to reveal a faster damage growth than the others. For $\rho=0.97 \%$, only the HSFRC $_{60}$ manages to enhance the cumulative damage index with respect to HSC with a value similar to that from the not being used up to their maximal efficiency. For $p$ $152 \%$, the HSFRC to thibis mo which underscores the inefficiency of fibers with the high, longitudinal reinforcement ratio.

\section{CONCLUSIONS}

The aim of this study has been to investigate the influence of fibers on the behavior of HSFRC beams under cyclic bending. The severe concrete damage due to alternate loading induces a loss in both maximal load capacity and ductility. This degradation suggests that the use of fibers can be efficient to prevent an early emergence of macrocracks during the prepeak stage. Fibers induce an increase in beam structural stiffness up to the peak load. For a tensile reinforcement ratio of $0.55 \%$. HSFRC exhibits behavior similar to that of an HSC beam with a tensile reinforcement ratio of $0.97 \%$. retion during, hearing
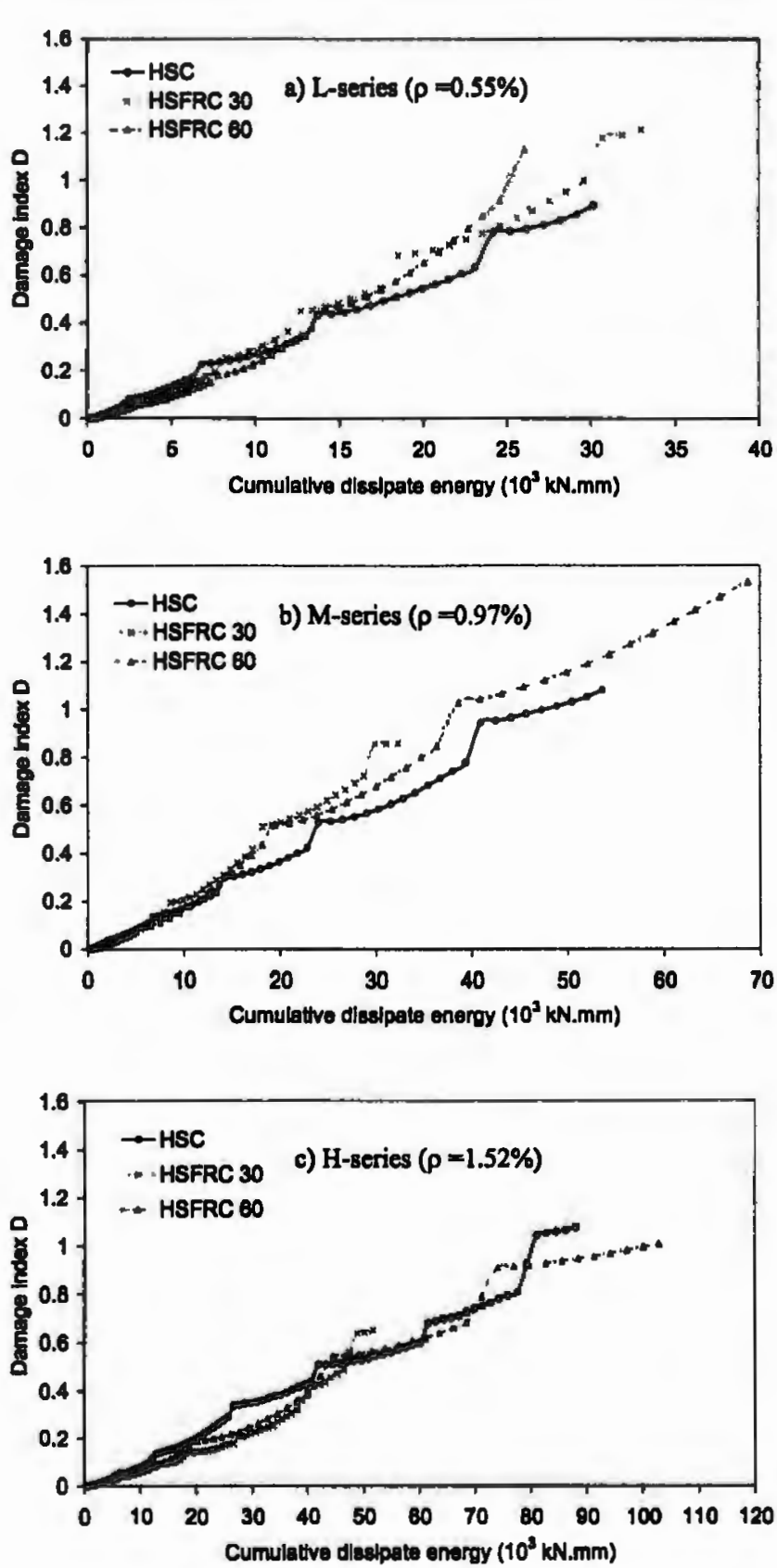

Fig. 11-Damage index $\mathrm{D}$ versus cumulative dissipate energy.

postpeak stage, the computation of ductility shows the diffculty involved in improving behavior. The increase loading capacity of HSFRC beams leads to a steeper slope of the postpeak branch.

Within an energy-based framework, however, and particwarly so in the case of earthquake zones, the insertion of long tibers enhances the energy dissipation over both the elastic and inelastic domains for all longitudinal reinforcement ratios; with regard to the $30 \mathrm{~mm}$ fibers, however, enhanced energy dissipation only occurs for lower ratios. With respect to energy dissipation alone, however, $30 \mathrm{~mm}$ thers may be recommended for lower reinforcement ratios. The effect on the cumulative damage capacity is positive for $60 \mathrm{~mm}$ fibers, with an efficiency limit for $\rho=1.52 \%$ These findings have raised the possibility of using the reinforco 
mechanical postpeak properties and energy dissipation in the inelastic domain.

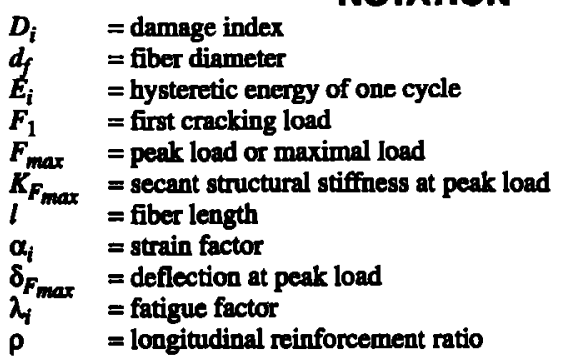

CONVERSION FACTORS
$1 \mathrm{~mm}=0.039 \mathrm{in}$.
$1 \mathrm{kN}=0.2248 \mathrm{kips}$
$1 \mathrm{MPa}=145 \mathrm{psi}$

\section{REFERENCES}

1. Collins, M. P.; Mitchell, D.; and Gregor, J. G., "Structural Design Considerations for High-Strength Concrete," Concrete Intermational, V. 15, No. 5, May 1993, pp. 27-34.

2. Gerard, B.; Marchand, J.; Breysse, D.; and Ammouche, A., "Constitutive Law of High-Strength Concrete under Tensile Strain," Intermational Symposium on Utilization of High-Strength/High-Pefformance Concrete, Paris, 1996, pp. 677-685.

3. Davidovici, V., "Génie parasismique," Presses de l'Ecole Nationale des Ponts et Chaussées, Paris, 1985.

4. Mansur, M. A.; Chin, M. S.; and Wee, T. H., "Flexural Behavior of High-Strength Concrete Beams," ACI Structural Joumal, V. 94, No. 6, Nov.-Dec. 1997, pp. 663-674.

5. Shin, S.-W.; Ghosh, S. K.; and Moreno, J., "Flexural Ductility of Ultra-High-Strength Concrete Members," ACI Structural Joumal, V. 86, No. 4, July-Aug. 1989, pp. 394-400.

6. Abrishami, H. H., and Mitchell, D. "Tnfluence of Steel Fibers on Tension Stiffening," ACI Structural Journal, V. 94, No. 6, Nov.-Dec. 1997, pp. $769-776$.

7. Li, Z; Li, F,; Chang, T.-Y. P.; and Mai, Y.-W., "Uniaxial Tensile Behavior of Concrete Reinforced with Randomly Distributed Short Fibers," ACI Materials Joumal, V. 95, No. 5, Sept-Oct. 1998, pp. $564-574$.

8. Hsu, L. S., and Hsu, C.-T. T., "Stress-Strain Behavior of Steel-Fiber High-Strength Concrete under Compression," ACI Structural Journal, V. 91, No. 4, July-Aug. 1994, pp. 448-457.

9. Casanova, P., "Bétons de fibres métalliques: du matériau à la structure," doctoral dissertation, Ecole Nationale des Ponts et Chaussees, France, 1996.

10. Espion, B.; Devillers, J.; and Halleux, P., "De l'utilisation de fibres métalliques comme armature complémentaire de poutres en béton arme soumises a la flexion," Materials and Structures, 1993, No. 26, pp. 479-485.

11. Chunxiang, Q., and Patnaikuni, I., "Properties of High-Strength Steel Fiber-Reinforced Concrete Beams in Bending," Cement and Concrete Composites, 1999, pp. 73-81.

12. Lemaitre, J., and Chaboche, J. L., "Mécanique des matériaux solides," Edition Dunod, 1988.

13. Popov, E. P., "Bond and Anchorage of Reinforcing Bars under Cyclic Loading," ACI JouRnal, Proceedings V. 81, No. 4, July-Aug. 1984, pp. 340-349.

14. Maurel, O., "Contribution à l'étude de la fissuration des membrures tendues en beton arme de hautes performances," thesis, Institut National des Sciences Appliquées de Toulouse, France, 1999.

15. Daniel, L.; Loukili A.; and Lamirault, J., "Experimental Behavior of High-Strength Fiber Concrete Beams under Cyclic and Alternated Loadings," Fifth RILEM Symposium on Fiber-Reinforced Concretes, Lyou, France, Sept. 13-15, 2000.

16. Kormeling, H. A.; Reinhardt, H. W.; and Shah, S. P., "Static and Fatigue Properties of Concrete Beams Reinforced with Continuous Bars and with Fibers," ACI Journal, Proceedings V. 77, No. 1, Jan.-Feb. 1980, pp. 36-43.

17. Rossi, P., "Les bétons de fibres métalliques," Presses de l'Ecole Nationale des Ponts et Chaussees, 1998.

18. Hamouine, A., "Contribution a l'étude de l'adhérence acier-béton de hautes performances," thesis, I.N.S.A. de Toulouse, May 1996.

19. Park, Y. J., and Ang, A. H. S., "Mechanistic Seismic Damage Model for Reinforced Concrete," ASCE Joumal of Structural Engineering, V. 3, 1985, pp. 722-757.

20. Srinivasa Rao, P.; Sivarama Sarma, B.; Lakshmanan, N.; and Stangenberg, F., "Damage Model for Reinforced Concrete Elements under Cyclic Loading," ACI Materlals Joumal, V. 96, No. 6, Nov.-Dec. 1998, pp. 682-690.

21. Danie1, L., and Loukili, A., "Cyclic Bending of High-Strength Fiber Reinforced Concrete Beams: Influence of Fiber Length," Thind International Conference on Concrete under Severe Conditions, V. 1, Vancouver, Canada, June 18-20, 2001, pp. 843-851.

22. Darwin, D., and Nmai, C. K., "Energy Dissipation of R/C Beams under Cyclic Load," Journal of Structural Engineering, ASCE, V. 112, No. 8, Aug. 1986, pp. 1829-1846.

23. Ehsani, M. R., and Wright, J. K, "Confinement Steel Requirements for Connections in Ductile Frames," ASCE Journal of Structural Engineering, V. 116, No. 3, 1990, pp. 751-767.

24. Meyer, I. F., "Ein werkstoffgerechtes Schädigungsmodell und Stababschnittselement fur Stahlbeton unter zyklisher nichtlinearer Beanspruchung," TR 88-4, RUB, Aug. 1988.

25. Sadeghi, K., "Simulation numérique du comportement de poteaux en béton armé sous cisaillement dévié alterne," thesis, Ecole Centrale de Nantes, France, 1995. 